\title{
microRNA-214 suppresses the growth of cervical cancer cells by targeting EZH2
}

\author{
YANLING YANG* ${ }^{*}$ YANG LIU* , GUILIN LI, LEI LI, PENG GENG and HONGJUAN SONG \\ Department of Gynecology, Xuzhou Maternity and Child Health Care Hospital, Xuzhou, Jiangsu 221009, P.R. China
}

Received September 18,2017; Accepted June 26, 2018

DOI: $10.3892 / \mathrm{ol} .2018 .9363$

\begin{abstract}
A number of studies have revealed the significance of microRNAs (miRs) in tumorigenesis. Cervical cancer (CC) is one of the most malignant cancer types and is associated with a poor overall survival rate. A previous study demonstrated a critical role of miR-214 in the development of multiple cancer types, but its role in $\mathrm{CC}$ remains elusive. In the current study, miR-214 was observed to be downregulated in $\mathrm{CC}$ tissues compared with the adjacent non-cancerous tissue. Overexpression of miR-214 reduced the proliferation of $\mathrm{CC}$ cells, whereas inhibiting its expression resulted in enhanced proliferation. Furthermore, Enhancer of zeste homolog 2 (EZH2) was demonstrated to be a direct target of miR-214 in CC. An MTT assay demonstrated that upregulating miR-214 expression or knocking down the expression of EZH2 impaired the proliferation of a CC cell line. Low expression of miR-214 was positively associated with tumor differentiation $(\mathrm{P}=0.037)$ and tumor stage $(\mathrm{P}=0.012)$. Notably, low expression of miR-214 predicted poor prognosis of patients with CC. Consequently, the results of the current study demonstrated that miR-214 functions as a tumor suppressor in $\mathrm{CC}$ and may be regarded as a potential therapeutic target in $\mathrm{CC}$.
\end{abstract}

\section{Introduction}

Cervical cancer (CC) is the fourth most common type of malignancy in women worldwide, accounting for $\sim 250,000$ cancer-associated mortalities annually $(1,2)$. The majority of CC cases are as a result of human papillomavirus (HPV) infections (3), which may explain why $\sim 80 \%$ of new CC cases are in developing countries $(4,5)$. An increasing number of studies have revealed that HPV infection alone is not sufficient

Correspondence to: Dr Hongjuan Song, Department of Gynecology, Xuzhou Maternity and Child Health Care Hospital, 46 He'ping Road, Xuzhou, Jiangsu 221009, P.R. China

E-mail: songhongjuan@foxmail.com

*Contributed equally

Key words: microRNA-214, cervical cancer, proliferation, Enhancer of zeste homolog 2 to initiate the malignant changes that lead to $\mathrm{CC}$, and that other factors contribute to the carcinogenesis and progression of CC $(6,7)$. Therefore, screening the factors involved in tumorigenesis may provide a new way to predict the progression of $\mathrm{CC}$ early or to efficiently treat patients with CC.

MicroRNAs (miRNAs or miRs) are a class of small noncoding RNAs that are 18-25 nucleotides in length, and which function as key regulators of gene expression at the post-transcriptional level (8). By targeting the 3'-untranslated regions (3'-UTRs) of target mRNAs, miRNA may lead to either translational repression or degradation of mRNA $(9,10)$. Several studies have demonstrated that miRNAs are involved in regulating various biological processes, including cell proliferation (11), migration (10), invasion $(10,12)$ and drug resistance (13). miR-214, one member of the miR-214 family, has been revealed to be aberrantly expressed in several human cancer types, including breast cancer (14), hepatocellular carcinoma (15), lung cancer (13), esophageal squamous cell cancer (16) and ovarian cancer (17). The dysregulation of miR-214 predicts a poor prognosis in the aforementioned cancers (13-17). Furthermore, the underlying molecular mechanism in these cancers has been explored, and a number of target genes, including PTEN, LHX6, GALNT7 and uncoupling protein 2 , have been identified $(13,15-17)$. However, the role of miR-214 in regulating human CC cells remains to be explored.

Enhancer of zeste homolog 2 (EZH2) serves an important role in regulating cell proliferation and the cell cycle via regulating the methylation status of lysine 27 in histone $\mathrm{H} 3$ (H3K27) $(18,19)$. A previous study demonstrated that overexpression of EZH2 is associated with worse disease-free survival rates and worse overall survival rates for patients with breast cancer (20). EZH2 was identified as a direct target of miR-214 in breast cancer (21). However, the association between EZH2 expression and miR-214 expression in human $\mathrm{CC}$ requires further exploration.

In the present study, the expression and biological function of miR-214 in human CC was evaluated. The expression of miR-214 was identified to be downregulated in CC tissues compared with the adjacent noncancerous tissues and EZH2 was identified as a direct target of miR-214. EZH2 knockdown or miR-214 overexpression could impair the cell proliferation of CC cell lines. Taken together, these results indicate that EZH2 may function as an oncogene and as a mediator of miR-214 in human CC. 


\section{Materials and methods}

Clinical tissue samples. A total of 45 patients diagnosed as $\mathrm{CC}$ were enrolled in the current study between August 2007 and October 2011, and none of them had received any anti-cancer treatments. Fresh CC tissues and corresponding adjacent noncancerous tissues were obtained from each of the enrolled patients. All tissue samples were stored in liquid nitrogen until further usage. The mean age of these patients was $53.5 \pm 7.4$ years, ranging between 45 and 69 years. The clinical information of CC cases is presented in Table I. Written informed consent was obtained from all enrolled patients. The current study was performed according to the principles of the Declaration of Helsinki. Ethics approval was granted by the Ethics Committee of the Xuzhou Maternity and Child Health Care Hospital (Xuzhou, China).

Cell culture. Human CC cell line HeLa and normal cervical cell line Ect1/E6E7 were purchased from the American Type Culture Collection (Manassas, VA, USA). These cells were cultured in RPMI 1640 medium (Invitrogen; Thermo Fisher Scientific, Inc., Waltham, MA, USA) supplemented with $10 \%$ heat-inactivated fetal bovine serum (Invitrogen; Thermo Fisher Scientific, Inc.), $100 \mathrm{IU} / \mathrm{ml}$ penicillin and $100 \mu \mathrm{g} / \mathrm{ml}$ streptomycin, in a humidified atmosphere of $95 \%$ air and $5 \%$ $\mathrm{CO}_{2}$ at a temperature of $37^{\circ} \mathrm{C}$.

Transient transfection. The miR-214 mimic (5'-UGCCUG UCUACACUUGCUGUGC-3'), miR-214 inhibitor (5'-GCA CAGCAAGUGUAGACAGGCA-3') and negative control miRNA (5'-GUGUCUGUCCUUACGUGCUCCA-3') were purchased from Guangzhou RiboBio Co., Ltd. (Guangzhou, China). The EZH2-targeting small-interfering RNA (siRNA; 5'-AGUCUCAUGUACGCTGACUCUG-3') and negative control siRNA (5'-GUGUCUUCACGUUACCUAGAGC-3') were also purchased from Guangzhou RiboBio Co., Ltd. All cell transfections were performed using Lipofectamine ${ }^{\circledR} 2000$ reagent (Invitrogen) according to the manufacturer's protocol and cultured for $48 \mathrm{~h}$ prior to the following experiments. The final concentration of miRNAs and siRNAs used for cell transfection was $100 \mathrm{~nm}$.

RNA isolation and reverse transcription-quantitative polymerase chain reaction ( $R T-q P C R)$. Total RNA was isolated from cultured cells and fresh-frozen tissues using TRIzol reagent (Invitrogen; Thermo Fisher Scientific, Inc.) according to the manufacturer's protocol. To quantify the expression level of miR-214, a total of $5 \mu \mathrm{g}$ RNA was reverse transcribed into cDNA using M-MLV reverse transcriptase (Promega Corporation, Madison, WI, USA). The temperature protocol of first-strand cDNA synthesis was: $16^{\circ} \mathrm{C}$ for $30 \mathrm{~min}, 42^{\circ} \mathrm{C}$ for $30 \mathrm{~min}$ and $85^{\circ} \mathrm{C}$ for $5 \mathrm{~min}$. The expression level of miR-214 was normalized to human U6 snRNA. The following PCR primers were used: U6: Forward, 5'-TGCGGGTGCTCG CTTCGGCAGC-3'; reverse, 5'-CCAGTGCAGGGTCCG AGGT-3' and miR-214: Forward, 5'-TGCGGACAGCAGGCA CAGAC-3'; reverse, 5'-CCAGTGCAGGGTCCGAGGT-3'.

The expression level of EZH2 was normalized to GAPDH. The following PCR primers were used: EZH2: Forward, 5'-TTGTTGGCGGAAGCGTGTAAAATC-3'; reverse, 5'-TCCCTAGTCCCGCGCAATGAGC-3' and GAPDH: Forward, 5'-TGAACGGGA AGCTCACTGG-3'; and reverse, 5'-TCCACCACCCTGTTGCTGTA-3'. RT-qPCR was performed using SYBR Premix Ex Taq ${ }^{\mathrm{TM}}$ kit (Takara Biotechnology Co., Ltd., Dalian, China) on the 7500 Real-Time PCR system (Applied Biosystems; Thermo Fisher Scientific, Inc.). The reaction condition was $95^{\circ} \mathrm{C}$ for $3 \mathrm{~min}$, followed by 40 cycles of $95^{\circ} \mathrm{C}$ for $30 \mathrm{sec}$ and $60^{\circ} \mathrm{C}$ for $30 \mathrm{sec}$. Relative expression values from three independent experiments were calculated using the $2^{-\triangle \triangle C q}$ method (22).

Western blot analysis. Total protein was isolated from cultured cells and tissues using RIPA lysis buffer (Beyotime Institute of Biotechnology, Haimen, China) and was quantified using a BCA protein quantification kit (Beyotime Institute of Biotechnology) according to the manufacturer's protocol. The protein samples $(50 \mu \mathrm{g})$ were separated using a $12 \%$ SDS-PAGE gel and then transferred to a polyvinylidene difluoride membrane (EMD Millipore, Billerica, MA, USA). The membrane was incubated with fat-free milk for $90 \mathrm{~min}$ at room temperature, then incubated with primary antibodies against EZH2 (cat. no. 4905) and GAPDH (cat. no. 2118; both 1:1,000; Cell Signaling Technology, Inc., Danvers, MA, USA) for $60 \mathrm{~min}$ at $4^{\circ} \mathrm{C}$. The membrane was then incubated with horseradish peroxidase-conjugated secondary antibodies (cat. no. 7074; 1:500; Cell Signaling Technology, Inc.) at room temperature for $60 \mathrm{~min}$. Bands were visualized using the BeyoECL Plus kit (Beyotime Institute of Biotechnology). Densitometric analysis of the protein bands was conducted using ImageJ 1.42 software (National Institutes of Health, Bethesda, MD, USA). Analysis of each sample was repeated three times.

Cell proliferation assay. To determine cell proliferation, an MTT assay was performed. Cells were seeded into 96-well plates at a density of $2 \times 10^{3}$ cells/well in a volume of $100 \mu 1$ RPMI 1640 medium supplemented with 10\% FBS, $100 \mathrm{IU} / \mathrm{ml}$ penicillin and $100 \mu \mathrm{g} / \mathrm{ml}$ streptomycin, and incubated for $0,24,48$ and $72 \mathrm{~h}$. MTT solution $(10 \mu \mathrm{l})$ was added to each well at a final concentration of $0.5 \mathrm{mg} / \mathrm{ml}$ and the cells were cultured for another $4 \mathrm{~h}$ at $37^{\circ} \mathrm{C}$. The medium was removed and the precipitated formazan was dissolved in $100 \mu 1$ DMSO. The absorbance of each well was measured at $570 \mathrm{~nm}$ using the Thermo Multiskan Spectrum spectrophotometer (Thermo Fisher Scientific, Inc.).

Target prediction and luciferase reporter assay. Based on bioinformatics prediction algorithm TargetScan 7.2 (http://www.targetscan.org/vert_72/), EZH2 was selected as a candidate target of miR-214. The 3'-UTR of EZH2 that contains the putative binding sites for miR-214 was amplified from human genomic DNA and cloned into the 3'-UTR of Renilla luciferase gene in the psiCHECK-2 receptor vector (Promega Corporation). The putative miR-214 binding sites in EZH2 were then mutated and also cloned into the psiCHECK-2 receptor vector. Following the cloning, the cells were co-transfected with miR-214 mimic or negative control miRNA and the wild-type or mutant 3'-UTR luciferase constructs using Lipofectamine 2000 reagent. Cells were lysed $24 \mathrm{~h}$ post-transfection to measure the luciferase activity 
Table I. Association between miR-214 expression and clinicopathological features.

\begin{tabular}{|c|c|c|c|c|}
\hline \multirow[b]{2}{*}{ Variables } & \multirow[b]{2}{*}{$\mathrm{n}$} & \multicolumn{2}{|c|}{$\begin{array}{c}\text { miR-214 } \\
\text { expression } \\
\text { level }\end{array}$} & \multirow[b]{2}{*}{ P-value } \\
\hline & & High & Low & \\
\hline Age, years & & & & 0.252 \\
\hline$\geq 50$ & 25 & 8 & 17 & \\
\hline$<50$ & 20 & 6 & 14 & \\
\hline Differentiation & & & & 0.037 \\
\hline Well/Moderate & 17 & 5 & 12 & \\
\hline Poor & 28 & 9 & 19 & \\
\hline Tumor stage & & & & 0.012 \\
\hline I-II & 16 & 6 & 10 & \\
\hline III & 29 & 8 & 21 & \\
\hline Lymph node metastasis & & & & 0.075 \\
\hline Negative & 18 & 5 & 13 & \\
\hline Positive & 27 & 9 & 18 & \\
\hline
\end{tabular}

miR-214, microRNA-214.

using a Dual-Luciferase Reporter Assay system (Promega Corporation), according to the manufacturer's protocol. Renilla luciferase activity was used to normalize the luciferase activity.

Statistical analysis. All statistical analyses were performed using GraphPad Prism 6.0 (GraphPad Software, Inc., La Jolla, CA, USA). The 75th percentile of the expression level of miR-214 was used to classify the patients into a high ( $\geq 75$ th percentile) or low ( $<75$ th percentile) miR-214 expression group. Data are presented as the mean \pm standard deviation (three repeats). $\chi^{2}$ test was used to evaluate associations between the expression of miR-214 and clinicopathological characteristics. Survival curves were generated using the Kaplan-Meier method and compared using the log-rank test. Comparisons between two groups were conducted using Student's t-test. Analysis of variance and Tukey's post-hoc test were used when comparing the differences among multiple groups. Cox univariate and multivariate regression analyses were used to identify the independent predictor for the prognosis of patients with CC. $\mathrm{P}<0.05$ was considered to indicate a statistically significant difference.

\section{Results}

miR-214 is downregulated in CC tissues and a CC cell line. To explore whether miR-214 expression was altered in CC, miR-214 expression levels in the $\mathrm{CC}$ and normal cervical cell lines were examined. As revealed in Fig. 1A, the expression of miR-214 in the CC cell line, HeLa, was significantly lower compared with that in the normal cervical cell line, Ect1/E6E7 $(\mathrm{P}<0.05)$. The cell proliferation in HeLa cells was significantly increased compared with the Ect1/E6E7 cells at $72 \mathrm{~h}(\mathrm{P}<0.001$; Fig. 1B). The expression of miR-214 was also investigated in the 45 pairs of $\mathrm{CC}$ tissues and corresponding adjacent non-cancerous tissues. Compared with the paired normal tissues, miR-214 expression was decreased in 31 of 45 CC tissues (68.89\%; Fig. 1C), which was demonstrated to be statistically significant $(\mathrm{P}<0.01$; Fig. 1D). The results demonstrated that the expression of miR-214 was downregulated in CC tissues and HeLa cells, which implies that miR-214 may serve an important role in the progression of CC.

miR-214 expression is associated with clinicopathological features of patients with $C C$. To investigate the association of miR-214 expression and the clinical outcome of patients with $\mathrm{CC}$, the 45 enrolled patients were classified into two groups based on the expression level of miR-214. The association between miR-214 expression and clinicopathological features was analyzed (Table I). miR-214 expression was significantly associated with tumor differentiation $(\mathrm{P}=0.037)$ and tumor stage $(\mathrm{P}=0.012)$, while no association was identified between miR-214 expression and age or lymph node metastasis. Patients with high miR-214 expression exhibited significantly higher overall survival probability compared with those with low miR-214 expression ( $\mathrm{P}=0.034$; Fig. 2 ) according to the Kaplan-Meier analysis and log-rank test results. These results indicated that miR-214 may contribute to CC progression. Additionally, a Cox univariate regression analysis revealed that low miR-214 expression $(\mathrm{P}=0.035)$, poor tumor differentiation $(\mathrm{P}=0.044)$ and high tumor stage $(\mathrm{P}=0.033)$ were associated with poorer survival rates of patients with CC (Table II). Similarly, a multivariate Cox regression analysis revealed that low miR-214 expression $(\mathrm{P}=0.036)$, poor tumor differentiation $(\mathrm{P}=0.042)$ and high tumor stage $(\mathrm{P}=0.020)$ could be regarded as independent indicators for poor survival of patients with CC (Table II).

Upregulating miR-214 expression inhibits the proliferation of CC cells. To further understand the biological function of miR-214 expression in CC progression, HeLa cells were transfected with an miR-214 mimic, an miR-214 inhibitor or negative control miRNA to regulate the expression level of miR-214. Successful transfection of the miRNAs was verified by RT-qPCR (Fig. 3A). The expression of miR-214 was significantly downregulated using a miR-214 inhibitor compared with the negative control ( $\mathrm{P}<0.05$; Fig. $3 \mathrm{~A})$, which significantly promoted HeLa cell proliferation $(\mathrm{P}<0.01$; Fig. 3B) compared with the negative control. Conversely, the expression of miR-214 was significantly upregulated using a miR-214 mimic $(\mathrm{P}<0.01$; Fig. 3A), which significantly inhibited HeLa cell proliferation $(\mathrm{P}<0.001$; Fig. $3 \mathrm{~B})$ compared with the negative control. Collectively, the results indicated that miR-214 serves as a proliferation inhibitor, which was consistent with the aforementioned finding that miR-214 expression was reduced in a CC cell line.

EZH2 is a direct target of miR-214. Using the online TargetScan algorithm, the 3'-UTR of EZH2 was identified to contain a putative target sequence for miR-214 (Fig. 4A). To validate EZH2 as a target of miR-214 in CC, the luciferase activities of EZH2 were analyzed using a dual-luciferase reporter assay. 

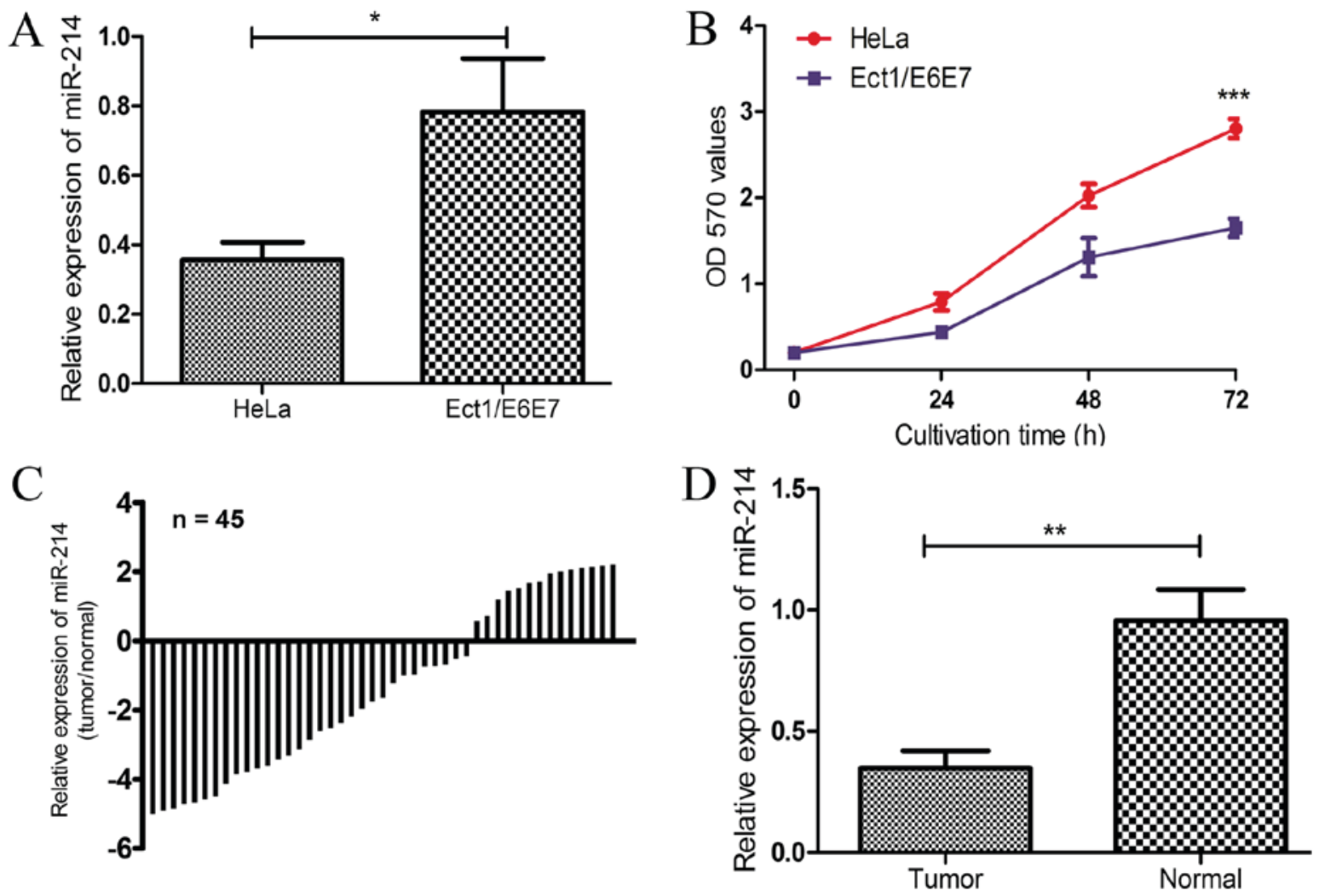

Figure 1. miR-214 is downregulated in human CC. (A) RT-qPCR analysis of miR-214 expression in the CC cell line, HeLa, and the normal cervical cell line, Ect1/E6E7. (B) MTT assay to analyze the cell proliferation rate of the HeLa and Ect1/E6E7 cell lines. RT-qPCR analysis of miR-214 expression was performed in tumor tissues and paired adjacent noncancerous tissues of 45 patients with CC; data are presented as (C) log2-fold change (cancer/normal) and (D) normalized against U6 snRNA. ${ }^{*} \mathrm{P}<0.05,{ }^{* *} \mathrm{P}<0.01 ;{ }^{* * *} \mathrm{P}<0.01$ vs. Ect1/E6E7. miR-214, microRNA-214; CC, cervical cancer; RT-qPCR, Reverse transcription-quantitative polymerase chain reaction; $\mathrm{OD}$, optical density.

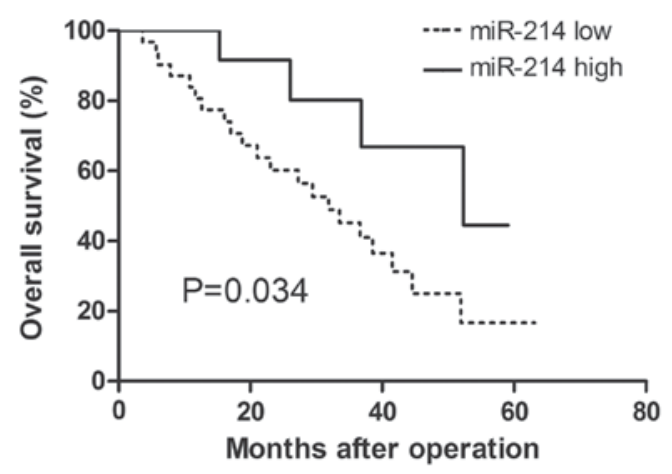

Figure 2. Kaplan-Meier overall survival curve for high and low miR-214 expression. The overall survival rates were measured in the high miR-214 expression group $(n=14)$ and the low miR-214 expression group $(n=31)$. miR-214, microRNA-214.

As expected, the miR-214 mimic significantly reduced the luciferase activity of the wild-type 3'-UTR of EZH2 compared with the negative control miRNA-transfected cells $(\mathrm{P}<0.001$; Fig. 4B). However, no significant differences were identified between cells transfected with negative control miRNAs and the miR-214 mimic when co-transfected with the mutated 3'-UTR of EZH2. The expression of EZH2 in HeLa cells transfected with an miR-214 mimic, an miR-214 inhibitor or negative control miRNA was measured. Upregulating miR-214 expression significantly downregulated the expression of EZH2, whereas downregulating miR-214 expression significantly upregulated the expression of EZH2 in HeLa cells compared with HeLa cells transfected with the negative control miRNA (both $\mathrm{P}<0.001$; Fig. 4C). Additionally, the expression of EZH2 in $\mathrm{CC}$ tissues and adjacent noncancerous tissues was examined and, as expected, the expression of EZH2 in CC tissues was significantly higher compared with that of the adjacent non-cancerous tissues $(\mathrm{P}<0.01$; Fig. 4D).

Inhibiting EZH2 expression reduces the proliferation of CC cells. To explore the effect of EZH2 on the proliferation capacity of HeLa cells induced by a miR-214 mimic, an EZH2-specific siRNA was introduced into HeLa cells. As revealed in Fig. 5A and B, EZH2-specific siRNA significantly downregulated the expression of EZH2 at the mRNA and protein levels (both $\mathrm{P}<0.01$ ). Furthermore, the proliferation of HeLa cells was significantly inhibited by EZH2-specific siRNA at $72 \mathrm{~h}(\mathrm{P}<0.01$; Fig. 5C). Taken together, these results demonstrated that miR-214 acts as a cell proliferation inhibitor partly through regulating the expression of EZH2.

\section{Discussion}

Dysregulation of miRNAs has been revealed in numerous human cancers and thus increasing research efforts have been made in this field $(9-17,23)$. It has previously been demonstrated that miRNAs may function as a novel class of tumorigenic and tumor-suppressing factors (24). miRNAs are involved 
Table II. Univariate and multivariate analyses of overall survival rate.

\begin{tabular}{|c|c|c|c|c|c|c|}
\hline \multirow[b]{2}{*}{ Variables } & \multicolumn{2}{|c|}{ Univariate analysis } & \multirow[b]{2}{*}{ P-value } & \multicolumn{2}{|c|}{ Multivariate analysis } & \multirow[b]{2}{*}{ P-value } \\
\hline & HR & $95 \% \mathrm{CI}$ & & HR & $95 \% \mathrm{CI}$ & \\
\hline microRNA-214 & 2.401 & $1.065-5.413$ & 0.035 & 2.392 & $1.060-5.397$ & 0.036 \\
\hline Age, years & 2.241 & $0.821-6.115$ & 0.115 & - & - & - \\
\hline Differentiation & 2.342 & $1.022-5.366$ & 0.044 & 2.556 & $1.034-6.314$ & 0.042 \\
\hline Tumor stage & 2.422 & $1.075-5.454$ & 0.033 & 2.728 & $1.169-6.366$ & 0.020 \\
\hline Lymph node metastasis & 2.438 & $0.945-6.292$ & 0.066 & - & - & - \\
\hline
\end{tabular}

HR, hazard ratio; CI, confidence interval.
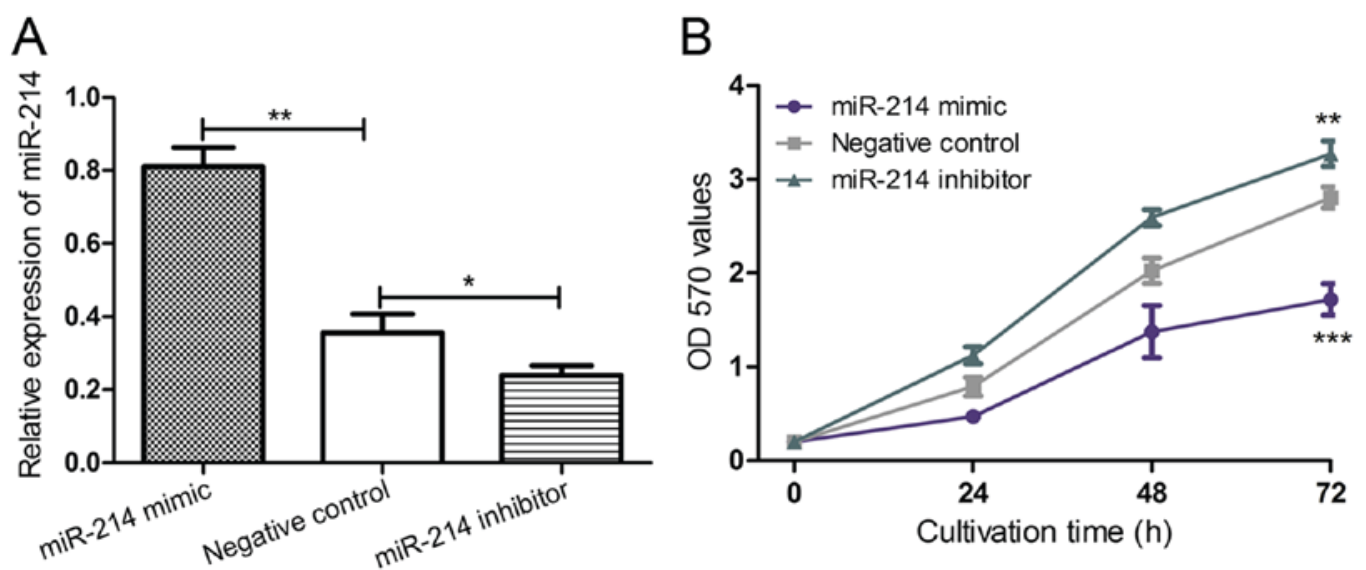

Figure 3. miR-214 overexpression inhibits proliferation of cervical cancer cells. (A) Reverse transcription-quantitative polymerase chain reaction analysis of miR-214 expression and (B) cell proliferation analysis using a MTT assay in HeLa cells following miR-214 mimic, miR-214 inhibitor or negative control miRNA transfections. In (A), $\mathrm{P}<0.05,{ }^{* *} \mathrm{P}<0.01$. In (B), ${ }^{* *} \mathrm{P}<0.01,{ }^{* * *} \mathrm{P}<0.001$ vs. negative control. miR-214, microRNA-214; OD, optical density.

in the tumor initiation and progression processes with two mechanisms: Certain miRNAs are directly involved in cancer development by controlling cell differentiation and apoptosis, and other miRNAs are involved in cancer by targeting cancer oncogenes and/or tumor suppressors (24). Understanding the molecular mechanisms of miRNAs in cancers may provide new insights into the molecular basis of cancers, and new biomarkers for cancer diagnosis and cancer therapy.

The differential expression of miR-214 in human cancers has been reported previously $(13,15-17)$. In the current study, a decrease in the expression of miR-214 was identified in human $\mathrm{CC}$ tissues and the CC cell line, HeLa, which is inconsistent with a previous study (25). In addition, the clinical significance of miR-214 expression in CC was studied. The current study demonstrated that low expression of miR-214 was associated with poor tumor differentiation and high tumor stage, and that patients with low miR-214 expression exhibited a worse 5-year overall survival rate. The multivariate analysis demonstrated that the miR-214 expression, tumor differentiation and tumor stage were independent predictors for the prognosis of patients with CC, which highlighted the importance of miR-214 expression in CC. Zhao et al (26) reported that the aberrant expression of miR-214 is associated with the growth of a lung cancer cell line. Therefore, the effect of miR-214 expression on HeLa cell proliferation was also investigated. In the current study, the transfection of an miR-214 mimic into HeLa cells resulted in the upregulation of miR-214, which led to decreased cell proliferation. The transfection of an miR-214 inhibitor into HeLa cells resulted in decreased miR-214 expression, but increased cell proliferation. This finding mirrors the role of miR-214 as a tumor suppressor gene. The deregulation of miR-214 in a CC cell line compared with a normal cervical cell line may account for the aberrant growth behavior of the CC cell line.

Several targets of miR-214, including ARL2, FOXM1 and HMGA1 have been identified in recent years (27-29). To explore the underlying mechanisms of the effects of miR-214 in CC, its potential target genes were explored using bioinformatics analysis and several genes were predicted as target genes of miR-214. The EZH2 gene was selected as a potential target to investigate in the current study as it was widely reported to be ectopically expressed in human cancers and associated with poor prognosis $(20,21,30)$. More importantly, EZH2 may be regulated by miR-214 in skeletal muscle cells (31), erythroid cells (32), cardiac myofibroblasts (33) and in the process of cardiac hypertrophy (34). Recently, Xu et al (35) demonstrated that EZH2 may also be regulated by miR-214 in glioma cells. Therefore, a dual-luciferase reporter assay was used in the current study to confirm that EZH2 is a direct target of miR-214 in CC. Notably, EZH2 expression may be regulated 
A

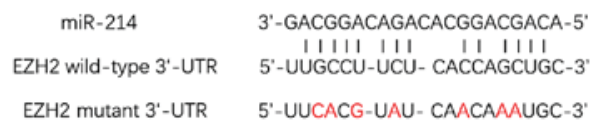

C

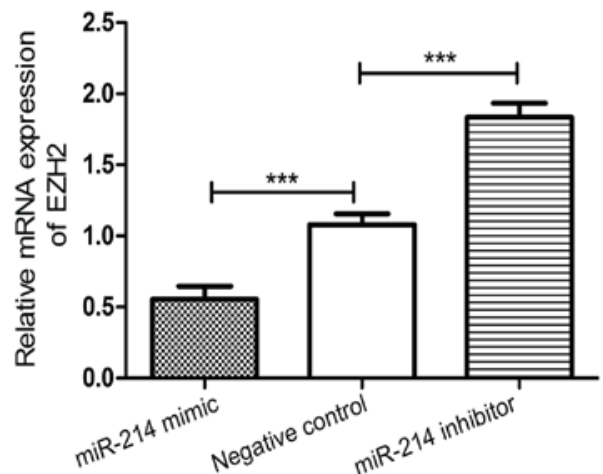

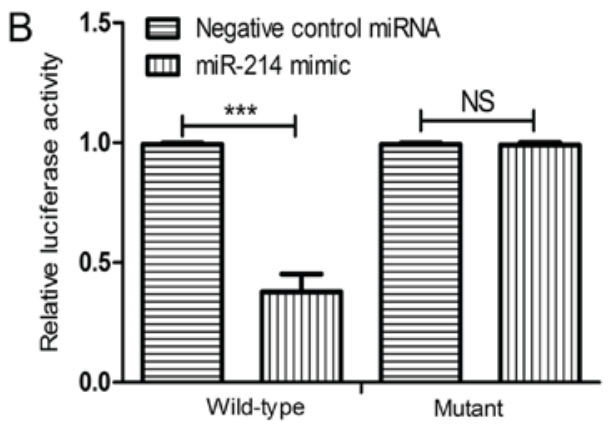

D
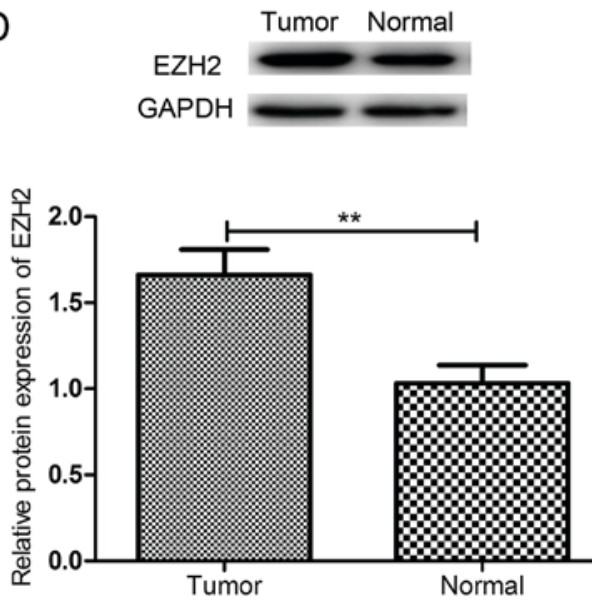

Figure 4. EZH2 is a direct target of miR-214. (A) Putative binding region between miR-214 and EZH2 mRNA. (B) A dual-luciferase reporter assay was performed on HeLa cells to detect the relative luciferase activities of wild type and mutant EZH2 reporters. (C) Reverse transcription-quantitative polymerase chain reaction analysis of EZH2 expression in HeLa cells following miR-214 mimic, miR-214 inhibitor or negative control miRNA transfections. (D) Western blot analysis of EZH2 expression in tumor tissues and paired adjacent non-cancerous tissues. ${ }^{* * *} \mathrm{P}<0.001,{ }^{* *} \mathrm{P}<0.01$. NS, not significant; miR-214, microRNA-214; EZH2, Enhancer of zeste homolog 2; UTR, untranslated region.

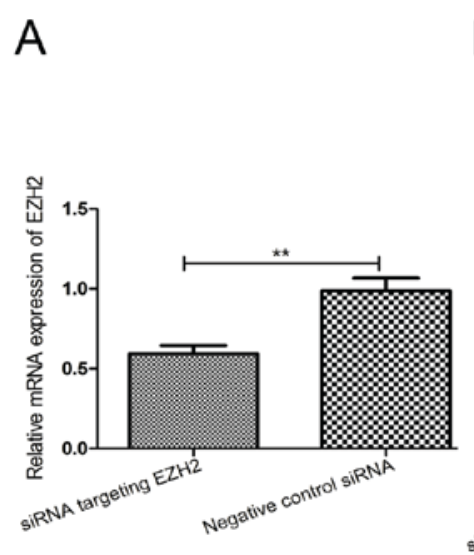

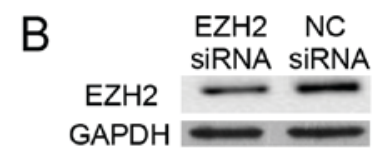

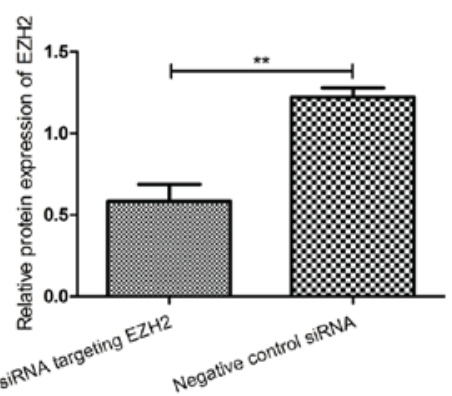

C

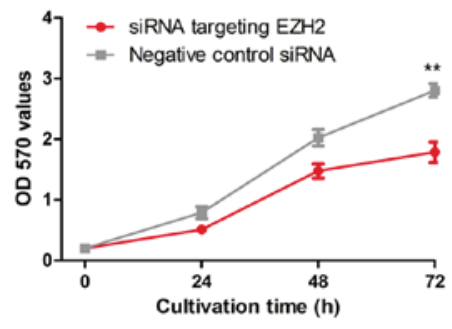

Figure 5. EZH2 downregulation inhibits cell proliferation of cervical cancer cells. (A) Reverse transcription-quantitative polymerase chain reaction and (B) western blot analyses of EZH2 expression in HeLa cells following siRNA targeting EZH2 and negative control siRNA transfections. ${ }^{* *} \mathrm{P}<0.01$. (C) An MTT assay was used to analyze the cell proliferation rate of HeLa cells following siRNA targeting EZH2 and negative control siRNA transfections. ${ }^{* *} \mathrm{P}<0.01$ vs. negative control. EZH2, Enhancer of zeste homolog 2; siRNA, small-interfering RNA; NC, negative control.

by miR-214, as the upregulation of miR-214 by a miR-214 mimic decreased EZH2 expression and the downregulation of miR-214 by a miR-214 inhibitor increased EZH2 expression in CC. Additionally, the role of EZH2 on HeLa cell proliferation was examined and, and as expected, downregulating the expression of EZH2 decreased cell proliferation, which is in accordance with a previous study (30). Taken together, these results indicate that EZH2 is a target gene of miR-214, which could potentially help to unravel the mechanism of miR-214 in the regulation of $\mathrm{CC}$ progression.

In conclusion, miR-214 was expressed at a low level in CC tissues when compared with adjacent non-cancerous tissues, and the overexpression of miR-214 inhibited cell proliferation. A novel target gene of miR-214, EZH2, was revealed to be upregulated in HeLa cells, a CC cell line. These findings indicated that inhibition of miR-214 in CC may contribute to 
the malignant phenotype by maintaining a high level of EZH2. Thus, the identification of miR-214 and its target gene, EZH2, in $\mathrm{CC}$ may aid in improving the prognosis for $\mathrm{CC}$ patients.

\section{Acknowledgements}

Not applicable.

\section{Funding}

No funding was received.

\section{Availability of data and materials}

The datasets used and analyzed during the present study are available from the corresponding author on reasonable request.

\section{Authors' contributions}

YY and YL contributed equally to the study. YY, YL and HS conceived and designed the study. YY, YL, GL, LL, PG and HS performed the experiments. YY, YL and HS wrote the paper. YY, YL and HS reviewed and edited the manuscript. All authors read and approved the manuscript.

\section{Ethics approval and consent to participate}

Ethics approval was granted by the Ethics Committee of the Xuzhou Maternity and Child Health Care Hospital (Xuzhou, China). Written informed consent was obtained from all participants.

\section{Patient consent for publication}

Written informed consent was obtained from all participants.

\section{Competing interests}

The authors declare that they have no competing interests.

\section{References}

1. Torre LA, Bray F, Siegel RL, Ferlay J, Lortet-Tieulent J and Jemal A: Global cancer statistics, 2012. CA Cancer J Clin 65: 87-108, 2015.

2. Torre LA, Siegel RL, Ward EM and Jemal A: Global cancer incidence and mortality rates and trends-an update. Cancer Epidemiol Biomarkers Prev 25: 16-27, 2016.

3. Small W Jr, Bacon MA, Bajaj A, Chuang LT, Fisher BJ, Harkenrider MM, Jhingran A, Kitchener HC, Mileshkin LR, Viswanathan AN and Gaffney DK: Cervical cancer: A global health crisis. Cancer 123: 2404-2412, 2017.

4. Chen W, Zheng R, Baade PD, Zhang S, Zeng H, Bray F, Jemal A, Yu XQ and He J: Cancer statistics in China, 2015. CA Cancer J Clin 66: 115-132, 2016.

5. Kent A: HPV vaccination and testing. Rev Obstet Gynecol 3: 33-34, 2010.

6. Hildesheim A and Wang SS: Host and viral genetics and risk of cervical cancer: A review. Virus Res 89: 229-240, 2002.

7. Martin CM, Astbury K and O'Leary JJ: Molecular profiling of cervical neoplasia. Expert Rev Mol Diagn 6: 217-229, 2006.

8. Calin GA, Dumitru CD, Shimizu M, Bichi R, Zupo S, Noch E, Aldler H, Rattan S, Keating M, Rai K, et al: Frequent deletions and down-regulation of micro-RNA genes miR15 and miR16 at 13q14 in chronic lymphocytic leukemia. Proc Natl Acad Sci USA 99: 15524-15529, 2002.
9. Ambros V: The functions of animal microRNAs. Nature 431: 350-355, 2004.

10. Liu Y, Hong W, Zhou C, Jiang Z, Wang G, Wei G and Li X: miR-539 inhibits FSCN1 expression and suppresses hepatocellular carcinoma migration and invasion. Oncol Rep 37: 2593-2602, 2017

11. Chen Z, Wang M, He Q, Li Z, Zhao Y, Wang W, Ma J, Li Y and Chang G: MicroRNA-98 rescues proliferation and alleviates ox-LDL-induced apoptosis in HUVECs by targeting LOX-1. Exp Ther Med 13: 1702-1710, 2017.

12. Zhu Y, Wu G, Yan W, Zhan H and Sun P: miR-146b-5p regulates cell growth, invasion, and metabolism by targeting PDHB in colorectal cancer. Am J Cancer Res 7: 1136-1150, 2017.

13. Liao J, Lin J, Lin D, Zou C, Kurata J, Lin R, He Z and Su Y: Down-regulation of miR-214 reverses erlotinib resistance in non-small-cell lung cancer through up-regulating LHX6 expression. Sci Rep 7: 781, 2017.

14. Liu B, Tian Y, Li F, Zhao Z, Jiang X, Zhao C, Han X and Zhang L: Tumor-suppressing roles of miR-214 and miR-218 in breast cancer. Oncol Rep 35: 3178-3184, 2016.

15. Yu G, Wang J, Xu K and Dong J: Dynamic regulation of uncoupling protein 2 expression by microRNA-214 in hepatocellular carcinoma. Biosci Rep 36: pii: e00335, 2016.

16. Lu Q, Xu L, Li C, Yuan Y, Huang S and Chen H: MiR-214 inhibits invasion and migration via downregulating GALNT7 in esophageal squamous cell cancer. Tumor Biol 37: 14605-14614, 2016.

17. Zhang Q and Zhang S: MiR-214 promotes radioresistance in human ovarian cancer cells by targeting PETN. Biosci Rep 27: BSR20170327, 2017.

18. Margueron R and Reinberg D: The Polycomb complex PRC2 and its mark in life. Nature 469: 343-349, 2011.

19. Di Croce L and Helin K: Transcriptional regulation by Polycomb group proteins. Nat Struct Mol Biol 20: 1147-1155, 2013.

20. Kleer CG, Cao Q, Varambally S, Shen R, Ota I, Tomlins SA, Ghosh D, Sewalt RG, Otte AP, Hayes DF, et al: EZH2 is a marker of aggressive breast cancer and promotes neoplastic transformation of breast epithelial cells. Proc Natl Acad Sci USA 100: 11606-11611, 2013.

21. Derfoul A, Juan AH, Difilippantonio MJ, Palanisamy N, Ried T and Sartorelli V: Decreased microRNA-214 levels in breast cancer cells coincides with increased cell proliferation, invasion and accumulation of the Polycomb Ezh2 methyltransferase. Carcinogenesis 32: 1607-1614, 2011.

22. Livak KJ and Schmittgen TD: Analysis of relative gene expression data using real-time quantitative PCR and the 2(-Delta Delta C(T)) method. Methods 25: 402-408, 2011.

23. Yang LH, Yin SY, He RQ, Mo WJ, Pang YY, Wu YZ, Peng ZG and Gan TQ: Prospective target genes and pathways of miR-30a-5p in colorectal cancer: An investigation using TCGA and bioinformatics analysis. Int J Clin Exp Med 10: 4373-4385, 2017.

24. Zhang B, Pan X, Cobb GP and Anderson TA: MicroRNAs as oncogenes and tumor suppressors. Dev Biol 302: 1-12, 2017.

25. Yang Z, Chen S, Luan X, Li Y, Liu M, Li X, Liu T and Tang H: MicroRNA-214 is aberrantly expressed in cervical cancers and inhibits the growth of HeLa cells. IUBMB Life 61: 1075-1082, 2009.

26. Zhao X, Lu C, Chu W, Zhang Y, Zhang B, Zeng Q, Wang R, Li Z, Lv B and Liu J: microRNA-214 governs lung cancer growth and metastasis by targeting carboxypeptidase-D. DNA Cell Biol 35: 715-721, 2016.

27. Peng R, Men J, Ma R, Wang Q, Wang Y, Sun Y and Ren J: miR-214 down-regulates ARL2 and suppresses growth and invasion of cervical cancer cells. Biochem Biophys Res Commun 484: 623-630, 2017.

28. Wang JM, Ju BH, Pan CJ, Gu Y, Li MQ, Sun L, Xu YY and Yin LR: MiR-214 inhibits cell migration, invasion and promotes the drug sensitivity in human cervical cancer by targeting FOXM1. Am J Transl Res 9: 3541-3557, 2017.

29. Chandrasekaran KS, Sathyanarayanan A and Karunagaran D: MicroRNA-214 suppresses growth, migration and invasion through a novel target, high mobility group AT-hook 1, in human cervical and colorectal cancer cells. Br J Cancer 115: 741-751, 2016.

30. Liu Y, Liu T, Bao X, He M, Li L and Yang X: Increased EZH2 expression is associated with proliferation and progression of cervical cancer and indicates a poor prognosis. Int J Gynecol Pathol 33: 218-224, 2014.

31. Juan AH, Kumar RM, Marx JG, Young RA and Sartorelli V: Mir-214-dependent regulation of the polycomb protein Ezh2 in skeletal muscle and embryonic stem cells. Mol Cell 36: 51-74, 2009. 
32. Gao M, Liu Y, Chen Y, Yin C, Chen JJ and Liu S: miR-214 protects erythroid cells against oxidative stress by targeting ATF4 and EZH2. Free Radic Biol Med 92: 39-49, 2016.

33. Zhu WS, Tang CM, Xiao Z, Zhu JN, Lin QX, Fu YH, Hu ZQ, Zhang Z, Yang M, Zheng XL, et al: Targeting EZH1 and EZH 2 contributes to the suppression of fibrosis-associated genes by miR-214-3p in cardiac myofibroblasts. Oncotarget 7: 78331-78342, 2016.

34. Yang T, Zhang GF, Chen XF, Gu HH, Fu SZ, Xu HF, Feng Q and Ni YM: MicroRNA-214 provokes cardiac hypertrophy via repression of EZH2. Biochem Biophys Res Commun 436: $578-584,2013$.
35. $\mathrm{Xu} \mathrm{C}, \mathrm{He} \mathrm{T}, \mathrm{Li} \mathrm{Z}, \mathrm{Liu} \mathrm{H}$ and Ding B: Regulation of HOXA11-AS/miR-214-3p/EZH2 axis on the growth, migration and invasion of glioma cells. Biomed Pharmacother 95: 1504-1513, 2017.

c) (i) (9) This work is licensed under a Creative Commons EY NG ND Attribution-NonCommercial-NoDerivatives 4.0 International (CC BY-NC-ND 4.0) License. 